\title{
Improving Heterogeneous Catalyst Stability for Liquid-phase Biomass Conversion and Reforming
}

\author{
Florent Héroguel, Bartosz Rozmysłowicz, and Jeremy S. Luterbacher ${ }^{\star}$
}

\begin{abstract}
Biomass is a possible renewable alternative to fossil carbon sources. Today, many bio-resources can be converted to direct substitutes or suitable alternatives to fossil-based fuels and chemicals. However, catalyst deactivation under the harsh, often liquid-phase reaction conditions required for biomass treatment is a major obstacle to developing processes that can compete with the petrochemical industry. This review presents recently developed strategies to limit reversible and irreversible catalyst deactivation such as metal sintering and leaching, metal poisoning and support collapse. Methods aiming to increase catalyst lifetime include passivation of low-stability atoms by overcoating, creation of microenvironments hostile to poisons, improvement of metal stability, or reduction of deactivation by process engineering.
\end{abstract}

Keywords: Biomass conversion - Catalyst stabilization - Deactivation · Heterogeneous catalysis · Process engineering

\section{Introduction}

Production of fuels and chemicals in the $20^{\text {th }}$ century has largely been focused on conversion of fossil resources. Crude oil was easily available at a relatively low extraction cost, and constituted a feedstock containing molecules of similar chemical properties. ${ }^{[1]}$ This led to the development of robust catalytic processes in the petrochemical industry. Hydrocarbon-based feeds with low oxygen content can be easily converted to transportation fuels, or catalytically cracked to elemental chemical building blocks and selectively oxidized to valuable chemicals. Most of those processes are solvent-free, and are often conducted in the gas phase at elevated temperatures. ${ }^{[2]}$ These features have made it possible for petrochemical conversion to operate at very large scale and to be very profitable. [3]
${ }^{*}$ Correspondence: Prof. Dr. J. S. Luterbacher Laboratory of Sustainable and Catalytic Processing Institute of Chemical Sciences and Engineering École Polytechnique Fédérale de Lausanne (EPFL) $\mathrm{CH}-1015$ Lausanne, Switzerland.

E-mail: jeremy.luterbacher@epfl.ch
However, despite the presence of these well-established and robust commercial processes for producing carbon-based products, there is increasing interest in finding renewable carbon sources to replace fossil resources. The geological timescales at which these fossil resources are created are much too long with respect to the rates at which they are consumed. For this reason, resource depletion appears inevitable. In addition, the global community is increasingly acknowledging the effect of fossil-based carbon emissions to the atmosphere, which have severe consequences with respect to climate change. This has led to new regulations ${ }^{[4]}$ forcing usage of biofuels and a general increased interest in biomass conversion in the past two decades. ${ }^{[5]}$

Biomass consists of three main groups of polymeric compounds: cellulose and hemicellulose, formed by carbohydrate monomers; and lignin, which is a complex polymer with aromatic functionalities. ${ }^{[6]}$ We have recently reviewed the targeted deconstruction of lignocellulosic material and the initial biomass deconstruction steps that generally produce the carbohydrate monomers of the aforementioned polysaccharides (mainly glucose and xylose), or the dehydration products of these monomers (including furans or levulinic acid).[7] Lignin deconstruction processes are much less mature, and most exploratory processes include the hydrogenolysis or oxidation to syringyl and guaicyl derivatives. ${ }^{[7,8]}$ These main routes for the deconstruction of biomass into platform molecules usually occur in water using various combinations of acids, ${ }^{[9,10]}$ bas- es, ${ }^{[11]}$ solvents ${ }^{[12-14]}$ or ionic liquids. ${ }^{[15,16]}$ All these methods typically produce soluble biomass-derived molecules at fairly low concentrations $(<20 \mathrm{~g} / \mathrm{L})$ in aqueous or solvent solutions, ${ }^{[7]}$ though some carbohydrate solutions can reach 100-220 g/L using solvent pretreatment and enzymatic hydrolysis $^{[17-19]}$ or solvent systems. ${ }^{[13,14]}$ Therefore, biomass-derived platform molecules are often produced in solution at fairly low concentrations.

Biomass-derived carbohydrates can also be converted to many other molecules by fermentation. Though combining chemical catalysis with biological conversion can dramatically increase the number of molecules that can be produced from biomass, these molecules also tend to be produced in fairly dilute aqueous streams. ${ }^{[20]}$ In addition, biological processes tend to introduce biogenic impurities including proteins and inorganic salts that can poison chemical catalysts. ${ }^{[20]}$ Finally, even pyrolysis oils - a third major source of biomassderived molecules - which are much more concentrated - usually contain significant amounts of water and nonvolatile compounds. Therefore, platform molecules derived from biomass are often produced in dilute liquid, and often aqueous, streams. Their high oxygen content makes them nonvolatile and vulnerable to degradation. Therefore, these molecules are usually further upgraded in the aqueous phase ${ }^{[21-24]}$ with reaction operation conditions limited to low temperatures by the low stability of the reactants, especially compared to petrochemical processes ${ }^{[25]}$ (Fig. 1).

While high catalytic activity is an important parameter for developing more 


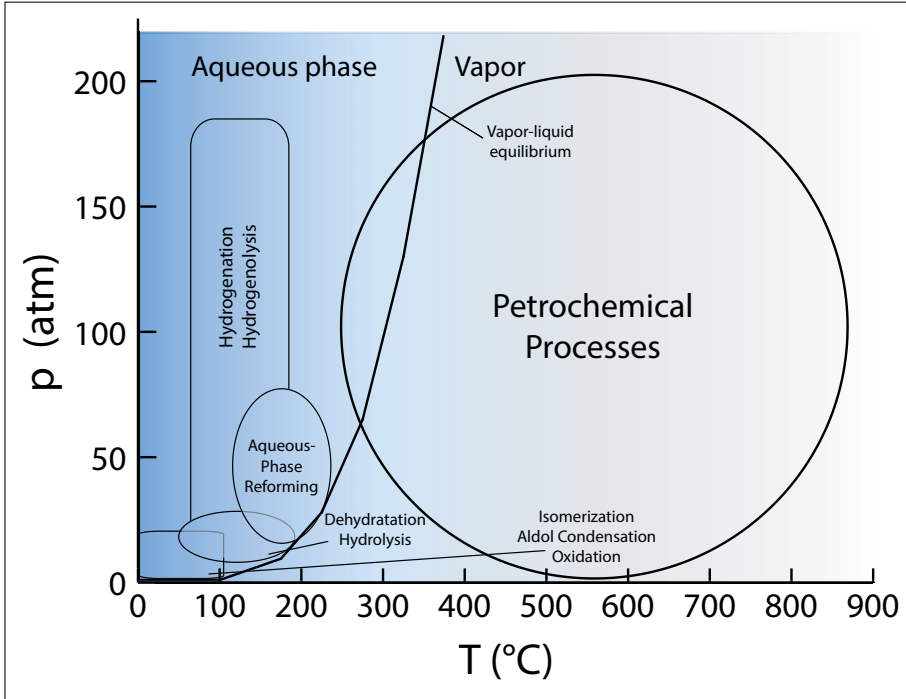

Fig. 1. Approximate reaction condition ranges for catalytic biomass conversion versus those for petroleum processes. Adapted from ref. [25]. competitive processes, catalyst lifetime is of prime importance under the harsh, often hydrothermal, conditions used for biomass conversion processes. Liquid-phase conditions can often increase the reactivity of catalyst surfaces. Furthermore, the water dissociation equilibrium is modified under hydrothermal conditions, during which the ionization constant increases from $10^{-14}$ at $25^{\circ} \mathrm{C}$ to $10^{-11}$ at $250{ }^{\circ} \mathrm{C}$. ${ }^{[26]}$ This results in higher ion concentrations that can perturb catalyst stability.[27] In addition, as mentioned above, biomass-derived feeds often contain high quantities of biogenic impurities that can act as catalyst poisons such as sulfur- or nitrogen-containing compounds, which can deactivate catalysts. This problem is often even more pronounced when a fermentation step is used. Given the extent to which biomass-derived feeds differ from petroleum-based feeds, shifting catalyst properties and robustness to meet these new demands is an important area of research. This review aims to address the main developments in the design of more stable catalysts for biomass conversion and reforming reactions (Fig. 2).

Supported metal particles are among the main catalyst families, and often display a limited stability independent of their preparation method. ${ }^{[28,29]}$ The main deactivation paths include sintering, which leads to a decrease in metal dispersion, ${ }^{[30]}$ leaching, i.e. metal dissolution, and pollution of surface metal with byproducts as coke. These phenomena dramatically decrease the amount of active metallic sites in the catalysts by reducing the ratio of active surface sites to inactive bulk metal in the case of sintering, removing active sites by leaching, or blocking active sites in the case of poisoning. This is especially problematic because the metallic particles are often the most expensive element of the catalyst.

The first section of this review reports on the major advances in catalyst design that aim to stabilize supported nanoparticles against sintering and leaching. Sintering and leaching reduce the amount of active sites and are irreversible deactivation pathways, i.e. initial properties cannot be recovered by regeneration such as calcination or reduction. In the second part of the review, we address catalyst poisoning and methods aiming to reduce it, during which an impurity or reaction byproduct (e.g. coke) blocks the active site. Even though this is a reversible deactivation, since the poison can be removed during

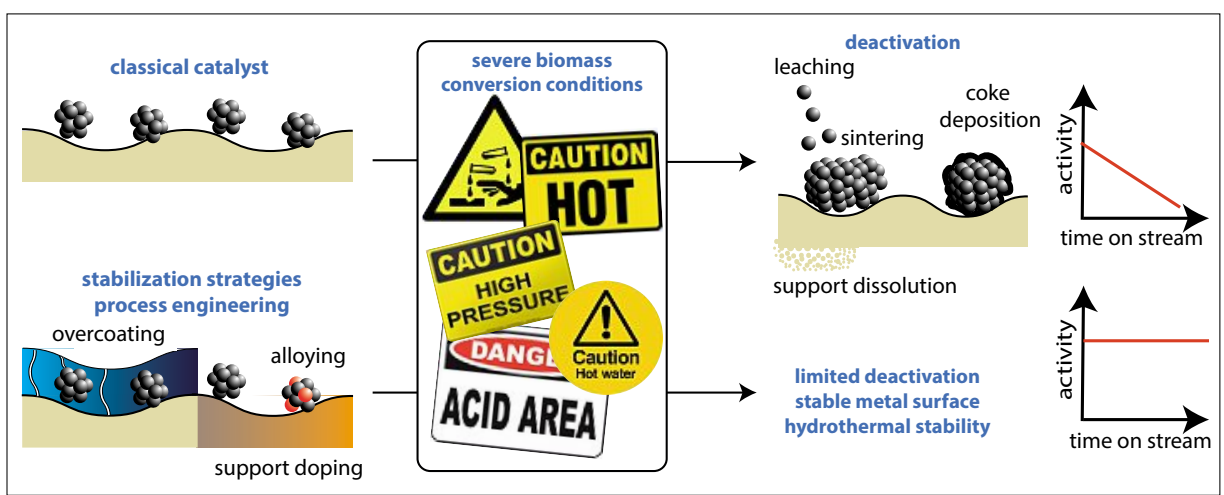

Fig. 2. Main deactivation pathways for solid catalysts for conversion of biomass and major catalysts stabilization concepts.

a regeneration cycle, regeneration cycles increase process costs and can themselves be problematic by modifying or destroying supports notably during high temperature calcination. In the third part, we discuss methods to improve stability of the support as opposed to just the nanoparticles. Finally, we discuss methods besides catalyst design, including tuning the process parameters, to increase catalyst stability and process lifetime. The main methods reviewed here as well as their commonalities are summarized in Table 1.

\section{Irreversible Deactivation via Sintering and/or Leaching of Supported NPs}

Sintering is one of the main deactivation pathways for supported metal nanoparticles, especially for catalytic processes performed at high temperatures. Understanding sintering is a prerequisite for the development of stable materials and has been the subject of several reviews. ${ }^{[30]}$ Sintering can occur via two distinct mechanisms: i) particle migration and coalescence, where particles statically move on the support surface and coalesce to form larger particles; and ii) Ostwald ripening, where particles size and geometry evolve to minimize free energy via adatom migration. In situ studies and Monte-Carlo simulations have helped to clarify the contribution of these two mechanisms. Initial rapid catalyst deactivation due to loss of metal surface area is attributed to Ostwald ripening, while particle migration and coalescence becomes preponderant in a second phase, once small metal particles have disappeared. ${ }^{[47]}$

Leaching is also a major issue for liquid phase processes, as it leads to both a decrease in activity and pollution of the product stream. Leaching occurs by extraction of individual metal atoms from particles into the solution via formation of free metal ions.

Many efforts have been dedicated to the stabilization of supported metal nanoparticles, ${ }^{[48]}$ and recent techniques involving deposition of a protective layer to prevent sintering and leaching of metal nanoparticles appear especially promising. Overcoating was first reported by $\mathrm{Lu}$ et al. for the stabilization of $\mathrm{Pd} / \mathrm{Al}_{2} \mathrm{O}_{3}$ during high-temperature dehydrogenation of ethane to ethylene. ${ }^{[39]}$ More recently, O'Neill et al. used the same strategy for the stabilization of alumina-supported copper nanoparticles by the deposition of an $\mathrm{Al}_{2} \mathrm{O}_{3}$ overcoat. ${ }^{[33]}$ Stabilization of copper was especially noteworthy because, while precious metal catalysts are generally preferred due to their great stability, base metals such as copper suffer from irreversible 
Table 1. Summary of the main catalyst stabilization strategies

\begin{tabular}{|c|c|c|c|c|c|}
\hline Deactivation pathway & Catalyst & Strategies & Method & Reaction & ref \\
\hline \multirow{4}{*}{$\begin{array}{l}\text { Metal leaching and } \\
\text { sintering }\end{array}$} & $\mathrm{Cu} / \mathrm{Al}_{2} \mathrm{O}_{3}$ & \multirow{3}{*}{$\begin{array}{l}\text { Overcoat to stabilize } \\
\text { undercoordinated atoms }\end{array}$} & \multirow[b]{2}{*}{$\mathrm{Al}_{2} \mathrm{O}_{3} \mathrm{ALD}$} & Furfural hydrogenation & [31-33] \\
\hline & $\begin{array}{l}\mathrm{CuCr}_{2} \mathrm{O}_{4-}^{-} \\
\mathrm{CuO}\end{array}$ & & & Furfural hydrogenation & {$[34,35]$} \\
\hline & $\mathrm{Co} / \mathrm{TiO}_{2}$ & & $\mathrm{TiO}_{2} \mathrm{ALD}$ & $\begin{array}{l}\text { Aqueous phase hydro- } \\
\text { genation }\end{array}$ & {$[36]$} \\
\hline & $\mathrm{Ni} / \mathrm{CNF}$ & Avoid acidic conditions & $\begin{array}{l}\text { Increase } \mathrm{pH} \text { by } \\
\text { addition of } \mathrm{KOH} \\
\text { and hydrogen }\end{array}$ & Ethylene glycol conversion & {$[37]$} \\
\hline $\begin{array}{l}\text { Metal leaching and } \\
\text { sintering } \\
\text { Coke deposition }\end{array}$ & Co/HZSM-5 & $\begin{array}{l}\text { Embedment into support } \\
\text { structure }\end{array}$ & $\begin{array}{l}\text { Growth of HZSM-5 } \\
\text { onto } \mathrm{Co}_{3} \mathrm{O}_{3} / \mathrm{SiO}_{2}\end{array}$ & $\begin{array}{l}\text { Conversion of levulinic acid } \\
\text { to valeric biofuel }\end{array}$ & {$[38]$} \\
\hline \multirow[t]{2}{*}{ Coke poisoning } & $\mathrm{Cu} / \mathrm{Al}_{2} \mathrm{O}_{3}$ & $\begin{array}{l}\text { Mixed } \mathrm{Al}_{2} \mathrm{O}_{3}-\mathrm{MgO}_{\mathrm{x}} \\
\text { overcoat to decrease } \\
\text { support acidy }\end{array}$ & ALD & Furfural hydrogenation & {$[31]$} \\
\hline & $\mathrm{Pd} / \mathrm{Al}_{2} \mathrm{O}_{3}$ & $\begin{array}{l}\text { Overcoat to passivate } \\
\text { undercoordinated atoms }\end{array}$ & $\mathrm{Al}_{2} \mathrm{O}_{3} \mathrm{ALD}$ & $\begin{array}{l}\text { Dehydrogenation of ethane } \\
\text { to ethylene }\end{array}$ & [39] \\
\hline $\begin{array}{l}\text { Poisoning by amino } \\
\text { acids }\end{array}$ & $\mathrm{PdAu} / \mathrm{Al}_{2} \mathrm{O}_{3}$ & $\begin{array}{l}\text { Microenvironment hostile } \\
\text { to biogenic impurities }\end{array}$ & $\begin{array}{l}\text { Polymer cross- } \\
\text { linking }\end{array}$ & $\begin{array}{l}\text { Hydrogenation of triacetic } \\
\text { acid lactone }\end{array}$ & [40] \\
\hline \multirow{5}{*}{ Support dissolution } & $\begin{array}{l}\mathrm{Pd} / \mathrm{SiO}_{2} \\
\mathrm{Pd} / \mathrm{Al}_{2} \mathrm{O}_{3}\end{array}$ & \multirow{2}{*}{$\begin{array}{l}\text { Carbon overcoat to } \\
\text { increase hydrophobicity }\end{array}$} & $\begin{array}{l}\text { Sucrose pyrolysis } \\
\text { to form thin carbon } \\
\text { film }\end{array}$ & Hydrogenation of acetylene & [41] \\
\hline & $\begin{array}{l}\mathrm{Pt} / \mathrm{Al}_{2} \mathrm{O}_{3} \\
\mathrm{Ru} / \mathrm{Al}_{2} \mathrm{O}_{3}\end{array}$ & & $\begin{array}{l}\text { Formation of } \\
\text { graphitic carbon by } \\
\text { CLD }\end{array}$ & Ethylene glycol reforming & {$[42]$} \\
\hline & HY zeolite & $\begin{array}{l}\text { Hydrophobic micro- } \\
\text { environment }\end{array}$ & $\begin{array}{l}\text { Grafting silane } \\
\text { functionalities }\end{array}$ & Refining of pyrolysis oil & [43] \\
\hline & $\mathrm{Pd} /$ niobia & Formation of mixed oxide & $\begin{array}{l}\text { Doping by addition } \\
\text { of } 5 \% \mathrm{SiO}_{2}\end{array}$ & \multirow{2}{*}{ GVL to pentanoic acid } & [44] \\
\hline & $\begin{array}{l}\mathrm{Pd} / \mathrm{SBA} \\
\text { silica }\end{array}$ & $\begin{array}{l}\text { Deposition of hydrother- } \\
\text { mally stable overcoat }\end{array}$ & Niobia ALD & & {$[45]$} \\
\hline $\begin{array}{l}\text { Coke deposition and } \\
\text { dealumination }\end{array}$ & $\begin{array}{l}\text { Microporous } \\
\text { HZSM-5 }\end{array}$ & Change reaction media & Methanol co-feed & Bio-oil to hydrocarbons & {$[46]$} \\
\hline
\end{tabular}

deactivation through leaching and sintering under severe liquid-phase conditions. The latter catalyst was prepared by first forming $\mathrm{Al}_{2} \mathrm{O}_{3}$-supported copper oxide particles by incipient wetness impregnation of $\mathrm{Cu}\left(\mathrm{NO}_{3}\right)_{2}$ followed by reduction and passivation. The overcoat was then deposited by 45 successive cycles of Atomic Layer Deposition (ALD). Among various catalytic design techniques, ${ }^{[49]}$ ALD has been extensively used to tune properties at the molecular level. ${ }^{[50]}$ ALD allows deposition of thin layers $(<100 \mathrm{~nm})$ with high level of conformality. In comparison, state-ofthe-art catalyst preparation methods that include wet impregnation and deposition precipitation can lead to a mixture of sites, which result in side reactions. Therefore, despite the high price of ALD equipment and the limits of its applicability for industrial-scale preparation, ALD is a promising technique for catalyst modification and stabilization. In the case of $\mathrm{Al}_{2} \mathrm{O}_{3}$-ALD, deposition was achieved under vacuum at $200{ }^{\circ} \mathrm{C}$ by alternating cycles consisting of exposure of the substrate to an aluminum precursor (trimethyl aluminium or TMA) and water, as depicted on Fig. 3b.

Conventional ALD reactors designed for wafers cannot be employed for ALD on powders due to their high surface area. Fluidized bed reactors equipped with mechanical stirring or rotating chambers, which allow long contact times with precursors (> $30 \mathrm{~s}$, compared with $30 \mathrm{~ms}$ exposure for wafers substrates) were used in this and other work to uniformly coat supported catalyst and other high surface materials while preventing particle aggregation. ${ }^{[51-53]}$ When treating the $\mathrm{Al}_{2} \mathrm{O}_{3}$ supported copper particles, a continuous overcoat was formed, as shown by TEM pictures (Fig. 4a). In addition, both a significant surface area decrease (from 190 to $16 \mathrm{~m}^{2} / \mathrm{g}$ ) and the absence of accessible $\mathrm{Cu}^{0}$ sites detected by $\mathrm{N}_{2} \mathrm{O}$ chemisorption after reduction were observed. [33] Subsequent calcination at $700{ }^{\circ} \mathrm{C}$ under air flow allowed for pore formation within the overcoat (Fig. 3a) as attested by the surface area increase to $39 \mathrm{~m}^{2} / \mathrm{g}$ and re-exposure of the $\mathrm{Cu}^{0}$ sites $(23 \mathrm{vs} .86 \mathrm{mmol} / \mathrm{g}$ before coating). Stability of the catalysts was investigated in the hydrogenation of furfural to furfuryl alcohol in 1-butanol. After 1.5 days in stream, the catalyst had deactivated significantly and was regenerated by in situ calcination and reduction and catalytic activity was further tested (Fig. 4c and d). After four successive cycles, initial activity could not be recovered with the uncoated catalyst (Fig. 4c), which showed irreversible deactivation. In contrast, the overcoated $\mathrm{Cu} / \mathrm{Al}_{2} \mathrm{O}_{3}$ led to identical turnover frequencies over the course of several reaction/regeneration cycles in 1-butanol (Fig. 4c) and water (Fig. 4d). Irreversible deactivation was attributed to the decrease of metal surface area due to metal sintering as observed by TEM, which showed a notable particle size increase for the uncoated catalyst (Fig. 4b). Moreover, operando X-ray absorption spectroscopy studies confirmed that the overcoat provided stabilization by limiting sintering, most likely because of 

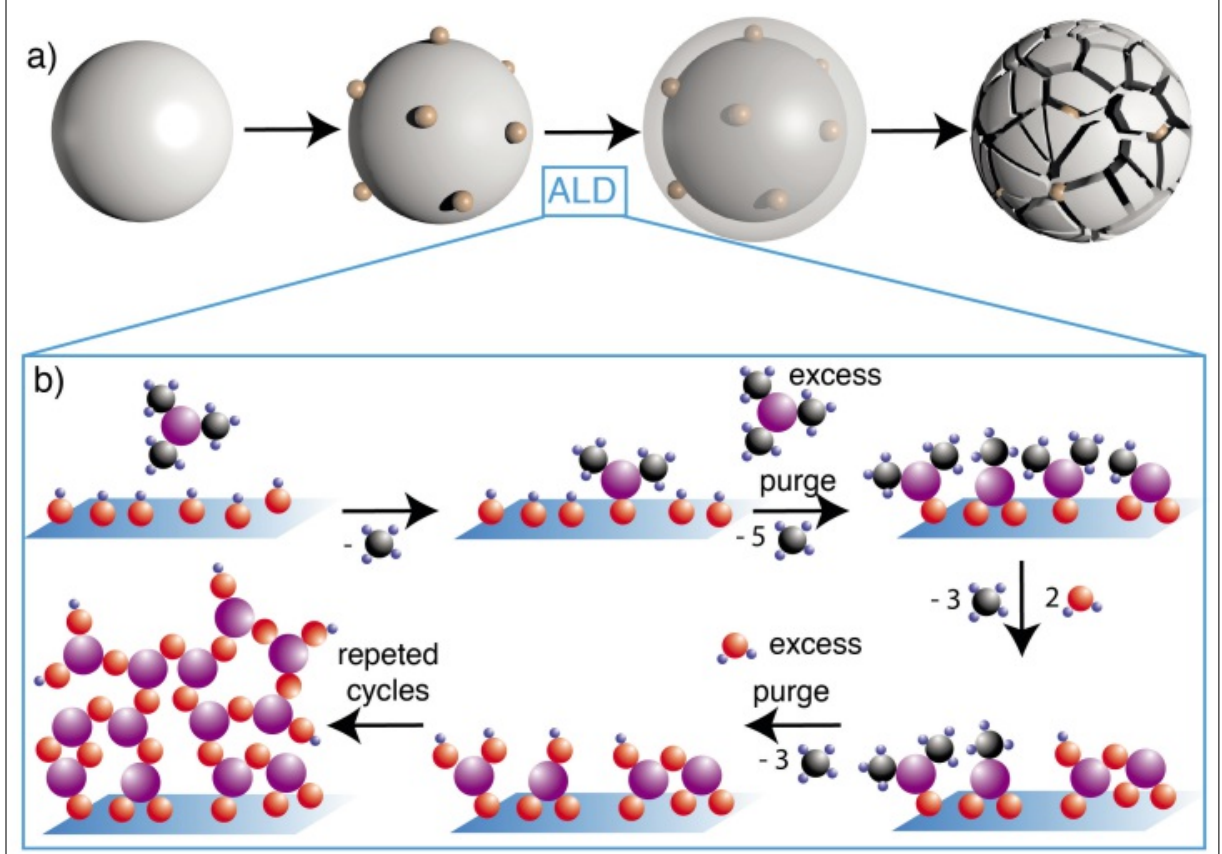

c)

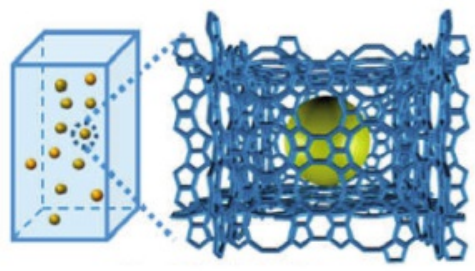

Fig. 3. a) Strategy for the synthesis of stable $\mathrm{Cu} / \mathrm{Al}_{2} \mathrm{O}_{3}$ catalysts: formation of $\mathrm{Al}_{2} \mathrm{O}_{3}$ supported copper particles, overcoating by ALD and cracking of overcoat by calcination; b) Mechanism of $\mathrm{Al}_{2} \mathrm{O}_{3} \mathrm{ALD}$ on $\mathrm{Al}_{2} \mathrm{O}_{3}$ (red: O; purple: Al; black: C; blue: $\mathrm{H}$ ); c) Embedment of Co onto HZSM-5 matrix. Reproduced with permission from ref. [38]. Copyright 2014 American Chemical Society. high activity but low stability while thick ALD overcoat (45 cycles) provided high stability but lower activities. The high activity of coated materials was attributed to an increased reduction temperature, which decreased the activation energy of furfural on $\mathrm{Cu}$ thanks to a modified ratio of $\mathrm{Cu}^{0}$, $\mathrm{Cu}^{+}$and $\mathrm{Cu}^{2+}$ species. Prior FTIR studies of adsorbed $\mathrm{CO}$ on $\mathrm{Pd}$ catalysts ruled out the existence of electronic effects between the ALD layer and metal nanoparticles. ${ }^{[39,54]}$ Rather, the authors suggested that the overcoat influences the transport of gas to and from the copper surface.

Besides $\mathrm{Al}_{2} \mathrm{O}_{3}$, successful $\mathrm{TiO}_{2} \mathrm{ALD}$ overcoating was used to stabilize $\mathrm{Co} /$ $\mathrm{TiO}_{2}$ during aqueous phase hydrogenation (APH) reactions. ${ }^{[36]}$ The analogous $\mathrm{Al}_{2} \mathrm{O}_{3}$ / $\mathrm{Co} / \gamma-\mathrm{Al}_{2} \mathrm{O}_{3}$ was inactive for the $\mathrm{APH}$ of furfural due to the formation of cobalt aluminate after calcination treatment, which was unreducible up to $800{ }^{\circ} \mathrm{C}$. Hence, the authors investigated the performances of $\mathrm{TiO} / \mathrm{Co} / \mathrm{TiO}_{2}$ prepared by ALD from $\mathrm{TiCl}_{4}$ on $\mathrm{TiO}_{2}$-supported Co particles. $\mathrm{H}_{2}$ temperature programmed reduction (TPR) revealed that switching from $\mathrm{Al}_{2} \mathrm{O}_{3}$ to $\mathrm{TiO}_{2}$ allowed reduction of $\mathrm{Co}$ at $600^{\circ} \mathrm{C}$, leading to furfural conversion. While the parent catalyst suffered from cobalt leaching $(10 \%$ Co lost over 2100 minutes), the metal loading of overcoated material remained constant even after regeneration. Finally, TEM study showed that the overcoat prevented a preferential interaction of the overcoat with undercoordinated $\mathrm{Cu}$ atoms which are more exposed to sintering and leaching. ${ }^{[32]}$ However, access to $\mathrm{Cu}$ sites decreased over time on stream due to coke deposit in the small pores in the overcoat leading to deactivation, reversible upon calcination. Finally, the overcoat did not influence selectivity as furfuryl alcohol remained the only hydrogenation product that was observed.

$\mathrm{Al}_{2} \mathrm{O}_{3}$ overcoating by ALD could also be used to increase the stability in gasphase reactions. Zhang et al. reported enhanced stability for the hydrogenation of furfural by ALD overcoating using copper chromite catalysts in the gas phase. ${ }^{[34,35]}$ Similarly to the $\mathrm{Cu} / \mathrm{Al}_{2} \mathrm{O}_{3}$ system described above, the overcoat preferentially blocked undercoordinated $\mathrm{Cu}$ atoms, which were present in the form of step edges and surface defects. The overcoat led to increased stability by decreasing three deactivation pathways: sintering of $\mathrm{Cu}$, coke formation, and coverage of active $\mathrm{Cu}$ sites by chromite migration. In addition, secondary reactions such as further dehydration of furfuryl alcohol to 2-methyl furan were disfavored when covering undercoordinated atoms resulting in higher furfuryl alcohol selectivity. Thin ALD overcoat (10 cycles) showed
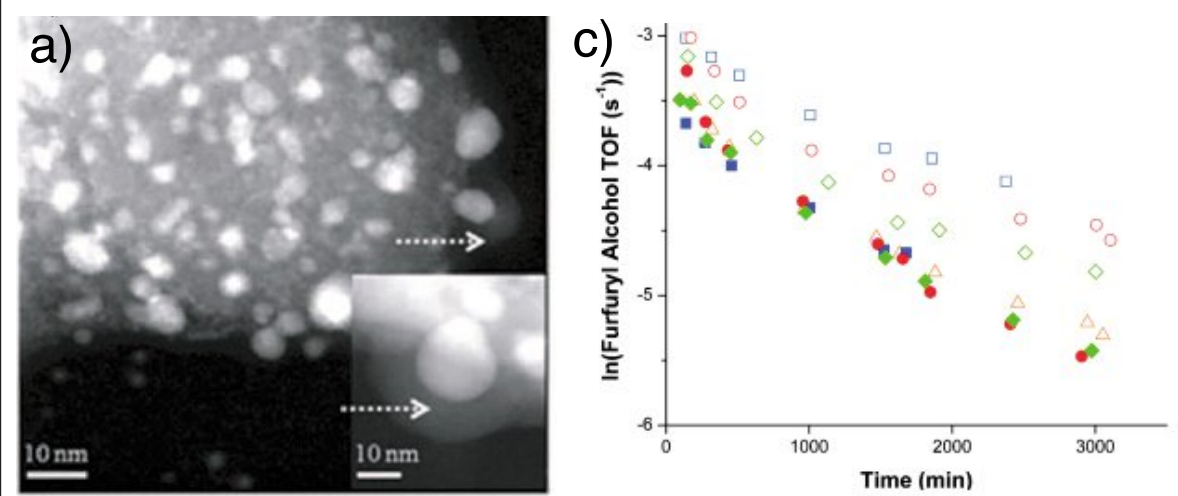

b)
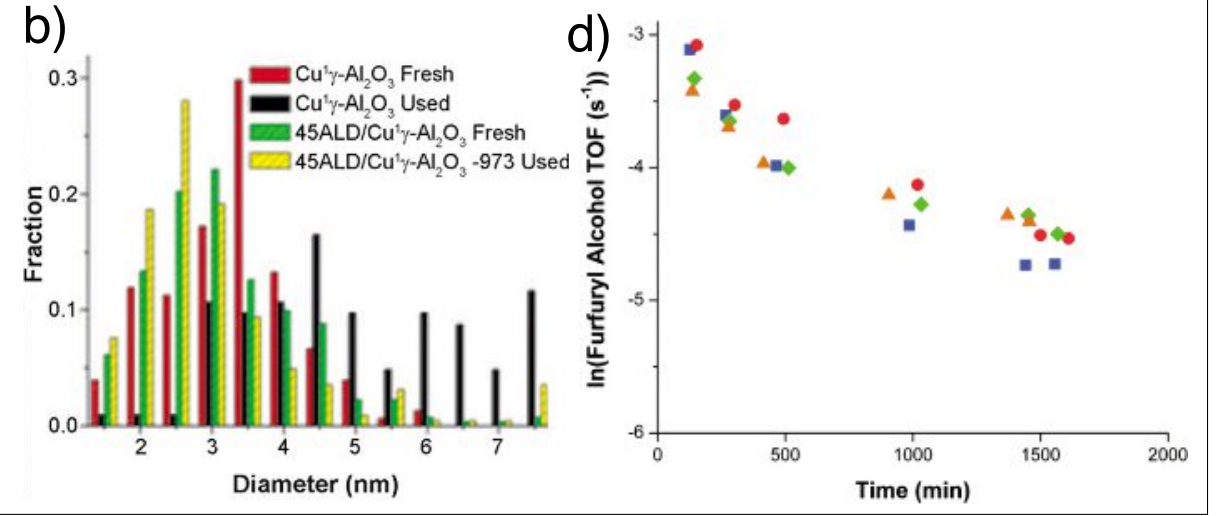

Fig. 4. STEM image of $45 \mathrm{ALD} / \mathrm{Cu} / \mathrm{Al}_{2} \mathrm{O}_{3}(\mathrm{a})$; Particle size distribution of fresh and used catalysts (b); TOF in furfural hydrogenation for $45 \mathrm{ALD} / \mathrm{Cu} / \mathrm{Al}_{2} \mathrm{O}_{3}$ (solid) and $\mathrm{Cu} / \mathrm{Al}_{2} \mathrm{O}_{3}$ (hollow) in 1-butanol (c) and water (d) (fresh $\square$; one regeneration O; two regenerations $\diamond$; three regenerations $\triangle$ ). Adapted with permission from Wiley-VCH Verlag from ref. [33]. 
the nanoparticles from sintering whereas sintering was observed during calcination in the absence of overcoat.

The methods above stabilized metal nanoparticles by adding a separate protective layer over selected parts of the support and metal particle surface. Sintering and leaching of base metal catalysts could also be limited by embedding the metal into a structure. ${ }^{[55]}$ For instance, Co nanoparticles were loaded into an HZSM-5 zeolite, providing a bifunctional catalyst for the conversion of levulinic acid into valeric biofuel, where cobalt performed hydrogenation while the acidic support catalyzed $\gamma$-valerolactone (GVL) ring opening (Fig. 3c). ${ }^{[38]}$ In contrast to the incipient wetness impregnation approach, cobalt was embedded into HZSM-5 by nucleation and growth of HZSM-5 crystals onto $\mathrm{Co}_{3} \mathrm{O}_{4} /$ $\mathrm{SiO}_{2}$ whereas $\mathrm{SiO}_{2}$ was progressively dissolved thanks to the basicity of the system. $\mathrm{H}_{2}$-TPR showed a lower temperature for the reduction of cobalt oxide for the impregnated (Co/HZSM-5) compared to the embedded (Co@HZSM-5) catalyst, demonstrating a higher metal-support interaction for the latter. The strong interaction had a limited influence on the Co accessibility as demonstrated by a similar $\mathrm{H}_{2}$ uptake for both materials. Structural characterization was performed on Co/HZSM-5 and Co@HZSM-5 before and after catalysis to identify stability differences. First, TEM revealed a stable Co NPs size for Co@HZSM-5 while for Co/HZSM-5, the average Co NP size increased from 25 to $32 \mathrm{~nm}$. Second, coke formation was only detected for Co/HZSM-5 by thermogravimetric analysis (TGA) as well as $\mathrm{N}_{2}$ physisorption (decrease of surface area and pore volume). Finally, XRD patterns showed that both materials maintained their crystal structure.

Similar to $\mathrm{Cu}$ and $\mathrm{Co}$, supported $\mathrm{Ni}$ particles are relevant systems for the lowtemperature conversion of biomass-derived compounds - notably for lignin hydrogenolysis. ${ }^{[56-58]}$ However, as for many base metals, the Ni particles suffer from sintering. Nanoconfinement of $\mathrm{Ni}$ particles by self-assembly of $\mathrm{Ni}$ atoms inside the nanoribbons of hydrotalcite-derived mixed oxide provided increased catalytic stability for methane steam reforming, compared to Ni supported on commercial support surface. ${ }^{[59]}$ Metal embedment has also proven to be an efficient stabilization method for lactic acid production from glycerol. Morales et al. showed that MFI constituted a stabilizing matrix for $\mathrm{Sn}$ and significantly decreased leaching of said Sn while slowing down deactivation in comparison to bifunctional carbon-silica composites and BEA zeolites.[60]

Above, we discussed various methods demonstrating that controlling local nano- structures around the active metal catalyst could increase stability. Abdelrahman et al. recently showed that a simple judicious choice of the support could limit particle sintering during the hydrogenation of levulinic acid.[61] In fact, fast deactivation was observed for ruthenium particles supported on $\mathrm{SiO}_{2}$ while increased stability was achieved by using carbon and $\mathrm{TiO}_{2}$ as supports. $\mathrm{Al}_{2} \mathrm{O}_{3}$ was the support that led to the most stable catalyst, which the authors attributed to its lowest electronegativity.

Another strategy is to tune the composition of the metal itself. Formation of alloys for improved catalyst performances has often been used, including in reactions relevant to biomass conversion. ${ }^{[62]}$ In the case of SBA-15, the use of supported Ru$\mathrm{Fe}$ catalysts led to stable conversion and selectivities over $300 \mathrm{~h}$ with no aggregation of bimetallic particles, no structure collapse and improved selectivity for hydrogenation of acetic acid to ethanol compared to monometallic catalysts.[63]

Finally, while many efforts have been dedicated to the control of individual characteristics of supported metal nanoparticles and their immediate environment, Prieto et al. showed that controlling the collective properties of supported metal nanoparticles led to increased stability. ${ }^{[64]}$ By achieving near-maximum interparticle spacing for silica-supported copper nanoparticles, deactivation during methanol synthesis was limited with deactivation rates, which were an order of magnitude lower than those observed with a reference catalyst that had a non-uniform spatial distribution of particles.

\section{Poisoning of the Active Sites}

In addition to the reduction of the number of active sites by sintering and leaching, competitive adsorption of undesirable

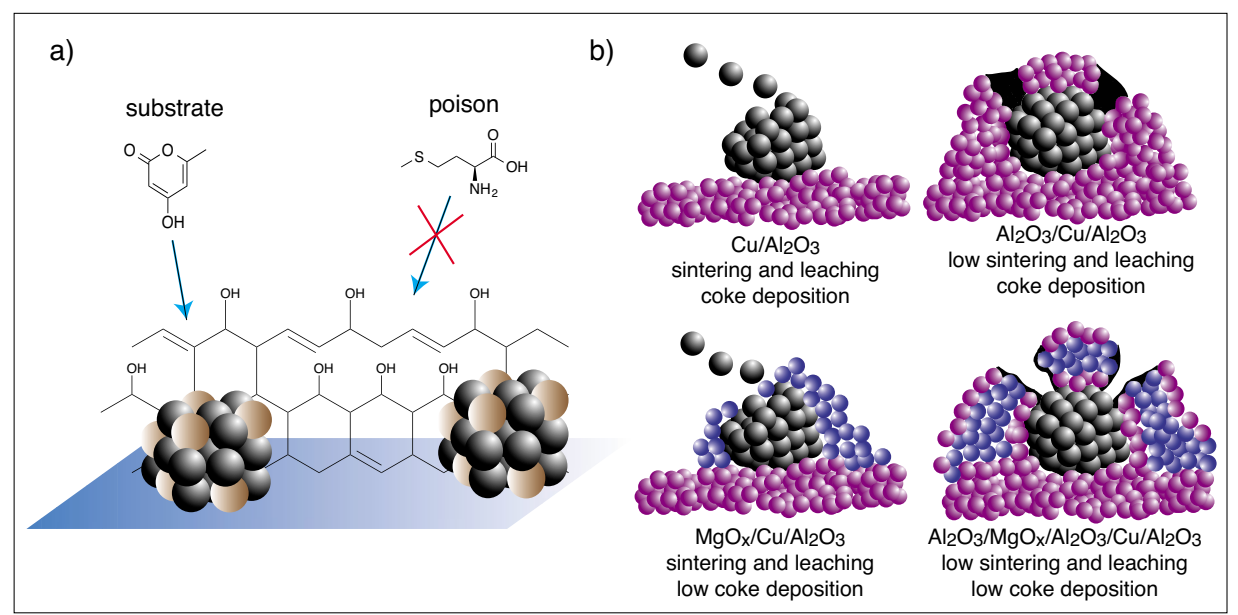

Fig. 5. a) Creation of microenvironment unfavorable to poisons. Adapted with permission from Wiley-VCH Verlag from ref. [40]; b) Stabilization of $\mathrm{Cu}$ (black)/ $\mathrm{Al}_{2} \mathrm{O}_{3}$ via $\mathrm{ALD}$ of $\mathrm{Al}_{2} \mathrm{O}_{3}$ (violet) and $\mathrm{MgO}_{\mathrm{x}}$ (blue). compounds such as coke or sulfur is a major catalyst deactivation pathway, because it leads to the blocking of active sites. be removed by regenerating the catalyst under oxidative or reductive media to form volatile species. However, these methods are sometimes incompatible with certain supports such as carbon, which has low thermal stability and will degrade during these regeneration treatments. In addition, processes not requiring periodic catalyst regeneration are generally favored for economic and practical reasons. Hence, several paths have been explored to limit catalyst poisoning.

Catalyst poisoning is often described as especially problematic in the context of fermentation-derived media, which has been proposed as an important source of biomass-derived platform molecules. ${ }^{[65]}$ In particular, sulfur-containing amino acids seem to be particularly detrimental to catalyst activity and are commonly found in fermentation broths. ${ }^{[65]}$ To alleviate deactivation by coke deposition of alumina-supported Pd catalysts during hydrogenation of fermentation-derived triacetic acid lactone (TAL), Schwartz et al. formed equimolar bimetallic PdAu particles. However, the alloy still suffered from sulfur poisoning similar to the parent monometallic catalyst when co-feeding model biogenic impurities such as methionine. The authors reasoned that a microenvironment unfavorable to polar species would limit deactivation by biogenic impurities while the reaction with the less polar substrate would still go forward. ${ }^{[40]}$ TAL is highly soluble in alcohols, whereas amino acids are not; hence, a poly(vinyl alcohol) (PVA) overcoat was selected to form a polymeric pseudo-solvent microenvironment (Fig. 5a). The PVA-overcoated $\mathrm{PdAu} / \mathrm{Al}_{2} \mathrm{O}_{3}$ catalyst displayed a deactivation rate of $0.02 \mathrm{~h}^{-1}$ vs $0.12 \mathrm{~h}^{-1}$ for the parent $\mathrm{Pd}$ / Some poisons, including coke, can often 
$\mathrm{Al}_{2} \mathrm{O}_{3}$ for initial conversions between 50 and $70 \%$. Stabilization by PVA was also highly efficient when using TAL produced by fermentation without any feed purification. Comparison of ${ }^{13} \mathrm{C} \mathrm{NMR}$ spectra of ${ }^{13} \mathrm{C}$-enriched methionine adsorbed on PVA-covered and non-covered $\mathrm{Pd} / \mathrm{Al}_{2} \mathrm{O}_{3}$ showed that the polymer acts as a 'solid solvent' by limiting methionine adsorption on $\mathrm{Pd}$.

The ALD overcoat strategy described in the previous section for metal sintering and leaching prevention has also proven useful for limiting coke deposition. Lu et $a l$. reported low reversible deactivation of overcoated $\mathrm{Pd} / \mathrm{Al}_{2} \mathrm{O}_{3}$ for the dehydrogenation of ethane to ethylene at $650{ }^{\circ} \mathrm{C} .{ }^{[39]}$ After using $45 \mathrm{ALD}$ cycles to form an $\mathrm{Al}_{2} \mathrm{O}_{3}$ thin film, the amount of coke deposited as determined by thermogravimetric analysis was more than 16 times lower than the amount measured for the parent $\mathrm{Pd} / \mathrm{Al}_{2} \mathrm{O}_{3}$ catalyst. The reduction of the amount of coke formed was attributed to the blocking of the low-coordination Pd surface sites, which were preferentially coated. In fact, the later sites favored $\mathrm{C}-\mathrm{C}$ bond scission and hydrogen stripping resulting in the undesirable formation of coke, $\mathrm{CH}_{4}, \mathrm{CO}$ and $\mathrm{CO}_{2}$. Hence, in addition to a lower catalyst deactivation, coating led to higher ethylene yields.

The $\mathrm{Al}_{2} \mathrm{O}_{3}$ overcoated $\mathrm{Cu} / \mathrm{Al}_{2} \mathrm{O}_{3}$ described earlier suffered from reversible coke deposition. In a separate study, the authors managed to limit this phenomenon by finely tuning the overcoat. In addition to the $\mathrm{Al}_{2} \mathrm{O}_{3}$ overcoat which provided particle stabilization, basic $\mathrm{MgO}_{\mathrm{x}}$ was deposited to reduce the overcoat's acidity, which was assumed to catalyze the formation of coke (Fig. 5b). ${ }^{[31]}$ Interestingly, pure $\mathrm{MgO}_{\mathrm{x}} \mathrm{did}$ not provide stabilization against sintering.

The local structure of the active site can also reduce poisoning by affecting local mass transfer. To suppress deactivation by fouling due to coke deposition during the conversion of propanal to hydrocarbons on Al-MFI, Luo et al. used an open mesoporous structure based on nanosheets to limit the effects of fouling. ${ }^{[66]}$ This strategy resulted in a five-fold decrease of deactivation rates. In addition to an increase in the number of pore openings, improved stability was attributed to the short diffusion path for reagents in the single unit-cellthick nanosheet material, which limited coke formation that was favored by longer contact times with the reaction products.

\section{Increasing Support Stability in Hydrothermal Conditions}

In addition to deactivation due to metal leaching and sintering, loss of surface area and pore collapsing in oxide supports is a major source of irreversible deactivation, especially in aqueous phase conditions. For biomass conversion processes, which often require liquid phase and/or aqueous media at low $\mathrm{pH}$, hydrothermal stability is a major concern. Metal oxides are often used as supports due to their thermal stability and high surface area. However, they tend to have low stability under the aforementioned conditions. ${ }^{[27]}$ Such oxides can sometimes be substituted by more stable support such as carbon but some processes require specific surface functionalities such as the acidic sites present on alumina. In addition, contrary to carbon, most oxides have excellent thermal stability, which is necessary during certain catalyst regeneration processes. Prominent supports such as alumina and silica-based materials undergo dissolution by hydrolysis of aluminoxane and siloxane bonds. In addition to loss of surface area, hydrolysis of oxide network can lead to modification of chemical composition. For instance, hydrolysis of the Si-O-Al bond in zeolites favors dealumination. This section describes the main techniques used to stabilize metal oxides supports in the area of biomass conversion.

Formation of mixed oxides or support doping can be used to limit this phenomenon. For instance, Pham et al. reported that the stability of $\mathrm{Pd} /$ niobia during transformation of $\gamma$-valerolactone (GVL) to pentanoic acid could be improved by addition of $5 \% \mathrm{SiO}_{2}$ into niobia. ${ }^{[4]}$ Niobia could not be entirely substituted by silica because acid sites are required for GVL ring opening, in addition to metal sites for the hydrogenation reaction. However, the addition of a small portion of $\mathrm{SiO}_{2}$ improves stability while retaining activity. The comparison of the $\mathrm{N}_{2}$ physisorption isotherms of a $\mathrm{Pd} /$ niobia $\mathrm{HY}$ commercial reference catalyst before and after the GVL reaction showed a dramatic surface area loss from 150 to $8 \mathrm{~m}^{2} / \mathrm{g}$ while the porous structure was affected to a lesser extent for $\mathrm{Pd} / \mathrm{Nb}-\mathrm{Si}$ oxide with a decrease from 81 to $31 \mathrm{~m}^{2} / \mathrm{g}$. Similarly, HAADF-STEM and HRTEM revealed a lower Pd particle growth upon reaction for the stabilized system than for the $\mathrm{Pd} / \mathrm{HY}$ reference catalyst. Similarly, Mazumder et al. reported the promotion of $\mathrm{Ni} / \gamma-\mathrm{Al}_{2} \mathrm{O}_{3}$ by $5 \mathrm{wt} . \% \mathrm{La}_{2} \mathrm{O}_{3}$ leading to dramatic improvement of activity and stability for the catalytic gasification of glucose compared to the parent catalyst which suffered from metal sintering. ${ }^{67]}$

The stabilizing oxide can also be introduced by ALD, similar to the thin overcoats deposited for the stabilization of supported metal particles as described in Section 2. For instance, hydrothermally stable $\mathrm{Nb}$-Si oxide catalysts were prepared using ALD of niobia within the pores of mesoporous silica SBA-15, using between 10 and 30 cycles which alternated exposure of the $\mathrm{Nb}\left(\mathrm{OCH}_{2} \mathrm{CH}_{3}\right)_{4}$ precursor and $\mathrm{H}_{2} \mathrm{O}$ to the SBA-15 surface (Fig. 6a). ${ }^{[45]}$ The consumption of silanol group on the surface was complete after 19 cycles, as

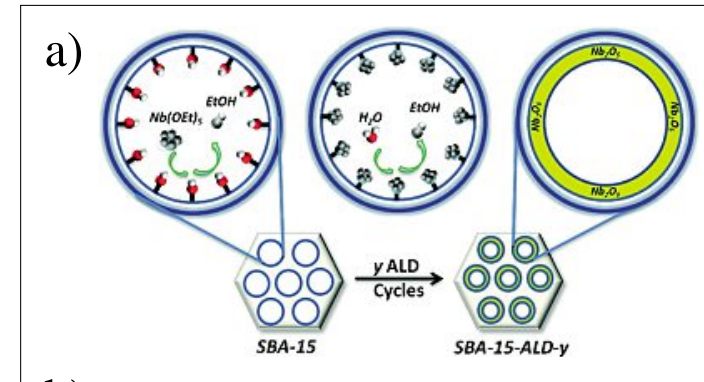

b)

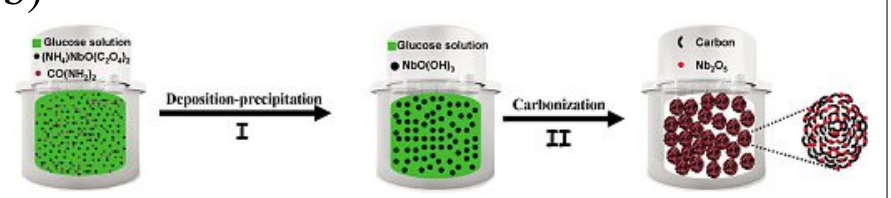

c)

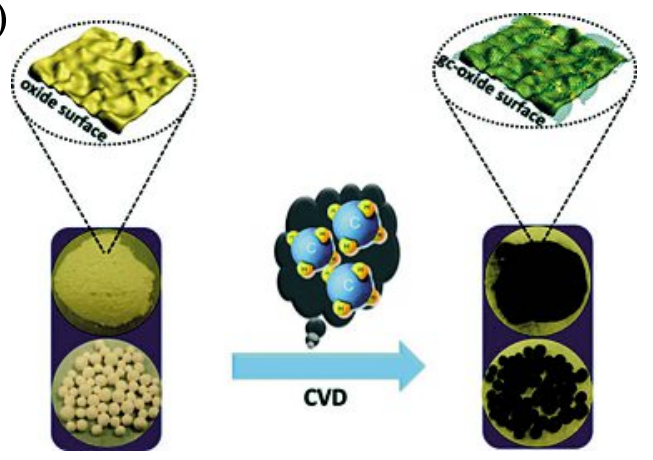

Fig. 6. a) Strategy for the synthesis of hydrothermally stable highly ordered niobia mesoporous materials by ALD. Reproduced with permission from ref. [45]. Copyright 2011 American Chemical Society; b) Strategy for the formation of niobia/ carbon composite catalysts. Adapted with permission of Elsevier from ref. [68]; c) Deposition of graphitic carbon layer on alumina powder and pellets by chemical layer deposition from $\mathrm{CH}_{4}$. Reproduced with permission from Wiley-VCH Verlag from ref. [42]. 
demonstrated by the disappearance of the $\mathrm{SiOH}$ band at $3735 \mathrm{~cm}^{-1}$ in the FTIR spectra. Hydrated amorphous niobia was identified as a major species by Raman spectroscopy for samples presenting 10, 19 and 30 ALD layers. $\mathrm{N}_{2}$ physisorption showed a decrease of surface area, pore volume and pore diameter with increasing niobia loadings. The presence of acid sites formed upon niobia deposition was verified by $\mathrm{NH}_{3}$-TPD and hydrothermal stability was tested by treating the materials in liquid water for $12 \mathrm{~h}$ at $200{ }^{\circ} \mathrm{C}$ and 28 bar argon. The structure of the coated materials after treatment was confirmed by X-ray diffraction with the persistence of the hexagonal mesoporous structure pattern while the latter pattern was suppressed after hydrothermal treatment of the parent SBA-15. TEM analysis confirmed the stability differences observed by XRD. A bifunctional catalyst for the transformation of GVL to pentanoic acid was also formed by subsequent deposition of Pd nanoparticles. As for the support, this catalyst showed higher stability than the conventional Pd/HY-340.

Improved hydrothermal stability of a niobia-supported $\mathrm{Pd}$ catalyst was also achieved by deposition of the latter on a more stable surface such as carbon. Highly dispersed spherical particles of a niobia/carbon composite were formed by the reaction of D-glucose and ammonium niobium oxalate in an autoclave at 200 ${ }^{\circ} \mathrm{C}$ (pH was controlled by urea decomposition) followed by pyrolysis at 400 ${ }^{\circ} \mathrm{C}$ under $\mathrm{N}_{2}$ (Fig. 6b). [68] Hydrothermal stability was investigated during liquidphase butanol dehydration at $240{ }^{\circ} \mathrm{C}$ and 51 bar. While initial activity of the composite bifunctional catalyst was lower than the commercial HY-340 catalyst, the latter quickly deactivated during the first 20 $\mathrm{h}$ of reaction while the modified catalysts remained very stable and surpassed HY340 after $8 \mathrm{~h}$. Interestingly, the analogous material obtained by incipient wetness impregnation of niobia led to the formation of large niobia crystallites, underscoring the importance of strong interaction between niobia and carbon. ${ }^{[69]}$ Finally, bifunctional catalysts were prepared by incipient wetness impregnation of $\mathrm{Pd}\left(\mathrm{NO}_{3}\right)_{2}$ and tested during the conversion of GVL to pentanoic acid, leading to improved hydrothermal stability for the niobia/carbon composite catalysts; just like the metal-free system.

For silica and alumina, improved hydrothermal stability above $100{ }^{\circ} \mathrm{C}$ was achieved by deposition of a thin film of carbon formed from simple sugars. Pham et al. deposited carbon by pyrolysis of adsorbed sucrose at $400{ }^{\circ} \mathrm{C}$ under $\mathrm{N}_{2}$ flow on SBA15 , silica gel, and fumed alumina, leading to improved stability after treatment in liquid water at $100{ }^{\circ} \mathrm{C}$ for 12 h. ${ }^{[41]}$ Moreover, $\mathrm{Pd}$ was deposited on the carbon-coated oxides to test their ability as supports for the catalytic hydrogenation of acetylene in the presence of excess ethylene. For a comparable Pd particle size $(1-1.5 \mathrm{~nm})$, the authors observed formation of ethane at high acetylene conversion on both $\mathrm{SiO}_{2}$ and $\mathrm{Al}_{2} \mathrm{O}_{3}$, while carbon-coating prevented over-hydrogenation to ethane. The FTIR study showed a low hydration potential for the coated materials compared to $\mathrm{SiO}_{2}$ and $\mathrm{Al}_{2} \mathrm{O}_{3}$. Therefore, the higher selectivity to ethylene for the coated materials was attributed to their increased hydrophobicity.

More recently, Xiong et al. reported on the deposition of a graphitic carbon layer over alumina by chemical vapor deposition (CVD) from $\mathrm{CH}_{4}$ (Fig. 6c). ${ }^{[42]}$ The graphitic carbon layer provided higher stability than the carbon deposited from pyrolysis of sugars as demonstrated by the higher stability achieved under flowing air (500 vs. $250{ }^{\circ} \mathrm{C}$ ). As monitored by the growth of the characteristic graphitic peak at $24^{\circ}$ $2 \theta$ on the XRD pattern, the amount of deposited carbon was controlled by the $\mathrm{CH}_{4}$ deposition time (from 0.5 to $6 \mathrm{~h}$ ) whereas other peaks attributed to $\gamma-\mathrm{Al}_{2} \mathrm{O}_{3}$ were untouched. TEM and energy-filtered TEM attested that the carbon coating was uniform on the oxide support. Raman spectroscopy mapping confirmed that deposition was uniform over the entire surface of the spheres. Furthermore, the relatively high ratio (0.71) between the peak intensities for $\mathrm{G}$ and $\mathrm{D}$ bands (at 1590 and $1350 \mathrm{~cm}^{-1}$, respectively) in the Raman spectrum of gc$\mathrm{Al}_{2} \mathrm{O}_{3}$ revealed a high degree of graphitization on the entire surface. No such features were observed for blank alumina and pyrolyzed carbon on alumina.

The hydrothermal stability of the catalyst was investigated using a treatment under static conditions at $220{ }^{\circ} \mathrm{C}$ under autogenic pressure in an autoclave using water. After treatment, the XRD pattern of $\gamma-\mathrm{Al}_{2} \mathrm{O}_{3}$ displayed the well-defined diffraction peaks of the boehmite phase attesting to a reaction with water. Simultaneously, no significant change was observed for graphitic-carbon covered $\gamma-\mathrm{Al}_{2} \mathrm{O}_{3}$ (gc$\mathrm{Al}_{2} \mathrm{O}_{3}$ ). Improved stability for $\mathrm{gc}-\mathrm{Al}_{2} \mathrm{O}_{3}$ was confirmed by $\mathrm{N}_{2}$ physisorption results, which showed that no significant decrease of surface area, pore volume and pore size occurred during hydrothermal treatment while $\gamma-\mathrm{Al}_{2} \mathrm{O}_{3}$ saw its surface area decrease by $80 \%$ during the same treatment. Stability of gc- $\mathrm{Al}_{2} \mathrm{O}_{3}$ as a support was tested in the aqueous phase reforming (APR) of ethylene glycol at $250{ }^{\circ} \mathrm{C}$ and 70 bar after deposition of platinum particles. Conversion using $\mathrm{Pt} / \mathrm{gc}-\mathrm{Al}_{2} \mathrm{O}_{3}$ was twice as high as for $\mathrm{Pt} / \gamma-\mathrm{Al}_{2} \mathrm{O}_{3}$. This result was consistent with the leached $\mathrm{Al}$ and $\mathrm{Pt}$ detected in the liquid phase after reaction by ICP-OES for the uncoated material. In addition to full conversion of $\gamma-\mathrm{Al}_{2} \mathrm{O}_{3}$ to boehmite observed by XRD, STEM showed Pt particle size increase for $\mathrm{Pt} / \gamma$ $\mathrm{Al}_{2} \mathrm{O}_{3}$. Hence, deactivation of $\mathrm{Pt} / \gamma-\mathrm{Al}_{2} \mathrm{O}_{3}$ was also attributed to $\mathrm{Pt}$ particle sintering in addition to leaching, whereas the use of graphitic carbon overcoat prevented both phenomena under APR conditions. This approach was also successful when using $\mathrm{Ru} / \mathrm{gc}-\mathrm{Al}_{2} \mathrm{O}_{3}$ for lactic acid hydrogenation. Overall, graphitic carbon layers deposited through vapor phase route provided higher hydrothermal stability than pyrolytic carbon-coatings and seems to be a promising stabilization method for a wide range of applications.

In addition to the deposition of thin film, precise surface functionalization can also be used to improve catalyst stability. For instance, the generation of hydrophobic surfaces by grafting of octadecyltrichlorosilane groups on HY zeolite prevented the support structure from collapsing during stability tests, which mimicked the upgrading of biomass-derived liquid compounds in biphasic systems at $200{ }^{\circ} \mathrm{C}$. ${ }^{43]}$ Stabilization was attributed to a limited contact between the zeolite's hydrophobic surface and the aqueous phase. The same authors also reported a systematic study with various alkylsilanes from $\mathrm{C}_{2}$ to $\mathrm{C}_{18}{ }^{.}{ }^{[70]}$

Hydrothermal stability of zeolites has been studied in great detail, as zeolites are the most widely used solid acid catalysts ${ }^{[71]}$ and are often proposed for biomass conversion. ${ }^{[72,73]}$ As shown by detailed characterization using ${ }^{27} \mathrm{Al}$ and ${ }^{29} \mathrm{Si}$ solid-state NMR and $\mathrm{NH}_{3}-\mathrm{TPD}$, siloxane bridge hydrolysis was the main deactivation route in the presence of hot liquid water while zeolites treated under steam suffered from dealumination. ${ }^{[74]}$ After a treatment in hot water at $200{ }^{\circ} \mathrm{C}$, mimicking APR conditions, ZSM-5 was stable independent of its $\mathrm{Si} / \mathrm{Al}$ ratio while degradation of zeolite $\mathrm{Y}$ increased with increasing $\mathrm{Si} / \mathrm{Al}$ ratio, as opposed to the better stability of zeolites with higher $\mathrm{Si} / \mathrm{Al}$ in the presence of steam. Finally, Al-rich zeolite Y could be stabilized by incorporation of lanthanum cations. ${ }^{[74]}$

Recently, Gardner et al. reported that testing the hydrothermal stability of zeolites in distilled water was not completely relevant to biomass conversion reaction conditions. ${ }^{[75]}$ In fact, dry biomass contains about 1.5 wt.\% of inorganic salts such as $\mathrm{NaCl}$ and the dissolution rate of metal oxides could be dramatically enhanced by cations in solution. ${ }^{[76]}$ Catalytic tests showed that the presence of $\mathrm{NaCl}$ had no influence on glucose conversion during the liquid-phase transformation of glucose to HMF on ZSM-5. However, zeolite hydrothermal stability was significantly perturbed by the presence of $\mathrm{NaCl}$, leading to the hydrolytic attack of extra-framework species and/or defects sites. Interestingly, 
leached $\mathrm{Al}$ species were active in the conversion of glucose to fructose.

Together with metal particles, zeolites constitute an important class of bifunctional catalysts. While studies mentioned above aimed at adding a stabilizing element to an existing material, Ennaert et al. assessed the stability of Ru/zeolite H-USY in hot liquid water for the hydrolytic hydrogenation of cellulose using various $\mathrm{Si} / \mathrm{Al}$ ratios in order to select the optimal zeolite composition. ${ }^{[77]}$ They identified that the lattice was stabilized by framework aluminum atoms, which prevented hydrolysis of framework bonds, while the extra-framework aluminum atoms located at the external surface prevented zeolite solubilization. With a $\mathrm{Si} / \mathrm{Al}$ ratio greater than 3, a stable quantitative hexitol yield was obtained.

\section{Improving Catalyst Stability by Process Design}

Previous sections demonstrated how important smart catalyst design can be for prolonged catalyst lifetime. In addition, improved stability for a given catalyst can be achieved by tuning process parameters. In fact, proper reactions conditions such as the choice of gas atmosphere (e.g. hydrogen versus an inert gas) or concentration of reagents and solvents, can have dramatic effects on processes. As mentioned previously, leaching and sintering of metal nanoparticles tends to be more pronounced at low $\mathrm{pH}$. Nickel at $\mathrm{pH}$ values below 7 can be oxidized by water or acids ${ }^{[78]}$ to form $\mathrm{Ni}^{2+}$ species. ${ }^{[79]}$ To counterbalance this effect, van Haasterecht et al. used addition of $\mathrm{KOH}$ in ethylene glycol conversion over $\mathrm{Ni} / \mathrm{CNF}$ catalyst with $\mathrm{KOH}$ concentration between $0-1.2 \mathrm{M}$ to increase the $\mathrm{pH}$ and improve catalyst stability (Fig. 7).[37] $\mathrm{Ni}$ particles were less stable in hydrothermal conditions in comparison to ethylene glycol. In both cases, increasing the $\mathrm{pH}$ had a significant impact, though it was not as pronounced in ethylene glycol. Moreover, at very high $\mathrm{pH}(>13)$ sintering occurred again, which was probably due to a formation of highly mobile hydroxide nickel species.

A reductive gas atmosphere can lead to increased catalyst stability. A typical example is the aqueous phase reforming of ethylene glycol conducted over Ni-based catalysts. ${ }^{[37]}$ Introduction of hydrogen in the gas atmosphere suppressed the growth of nickel nanoparticles. The average particle size after reaction in a hydrogen and an inert atmosphere was 58 and $32 \mathrm{~nm}$, respectively. Moreover, leaching of the nickel decreased leading to $0.26 \%$ catalyst mass loss under inert atmosphere compared to $0.15 \%$ mass loss in hydrogen.

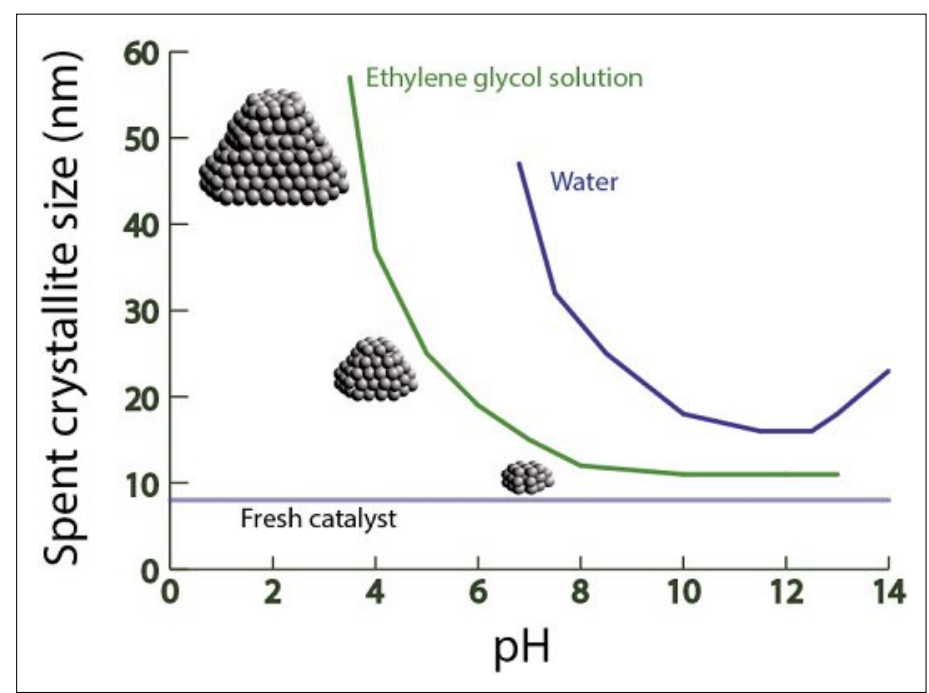

Fig. 7. Approximation based on experimental data between nickel nanoparticles size of the spent Ni/CNF catalysts and the $\mathrm{pH}$ of the final reaction mixture in aqueous phase reforming of ethylene glycol. The $\mathrm{pH}$ of the feed solutions was adjusted by addition of $\mathrm{KOH}(0-1.2 \mathrm{M})$ to aqueous solutions of $1 \mathrm{wt}$ \% ethylene glycol (green line) and to water (blue line). Reactions were performed at $230^{\circ} \mathrm{C}$ for $6 \mathrm{~h}$ under inert gas. Adapted with permission of Elsevier from ref. [37].

However, the use of hydrogen is not always beneficial. It was reported that for platinum supported on graphite at high $\mathrm{pH}$, under a hydrogen-rich atmosphere and at an elevated temperature, agglomeration of platinum could occur.[80] The reason was that removal of the graphite oxygen functional groups by hydrogen lead to lower adhesion and therefore higher mobility of the nanoparticles on the surface.

Coke formation over the catalyst can also be inhibited by co-feeding other substances to the reactor. For instance, in catalytic conversion of bio-oil into hydrocarbons, a stream of bio-oil was diluted with a ratio 1:2 with water, which decreased the mass of carbon deposits on microporous ZSM-5.[46] Unfortunately, this treatment led to irreversible catalyst deactivation due to dealumination of the zeolite caused by water at high temperature. ${ }^{[81,82]}$ However, the same authors found that the use of a 70 wt.\% methanol with a bio-oil mixture could decrease coke formation up to $70 \%$ and prevent dealumination and therefore maintain activity of the catalyst.

Preventing deactivation can also be achieved by controlling the reaction media. During the process of producing furfural from xylans, high deactivation of the GaUSY catalyst was observed when using water as a solvent. XRD analysis of the spent catalyst confirmed the collapse of the zeolite structure during reaction. Moreover, gallium content dramatically decreased after 24 hours of reaction from 5.9 wt. $\%$ to 0.27 wt. $\%$. To avoid the negative effects of water on the catalyst, the biphasic system water-methyl isobutyl ketone (MIBK) was used with a ratio of 20:80. Gallium leaching decreased during the first few hours (3.6 wt.\% Ga) and continued but at a lower rate to reach a metal content of $1.9 \mathrm{wt} . \%$ at the end of the reaction. Furthermore, XRD confirmed that the zeolite retained its structure at the end of the experiment confirming the importance of using a co-solvent. ${ }^{[83]}$

\section{Conclusions and Outlook}

Deactivation of catalysts under the harsh conditions used for biomass conversion is a bottleneck in the development of competitive processes for bioresource valorization to renewable alternatives to fossil-based fuels and chemicals. Biomassderived molecules that must be further upgraded are usually produced in relatively dilute liquid (often aqueous) streams, which contain biogenic and inorganic impurities. This introduces significant challenges for heterogeneous catalysts, which have often been developed in the context of reforming fairly pure gas-phase hydrocarbons. An important category of catalysts for catalytic biomass upgrading are oxidesupported metal particles due to their use in hydrogenation and hydrodeoxygenation reactions, are essential for removing oxygen from bio-based molecules. Several researchers have sought to reduce the main deactivation pathways for these catalysts; notably, their irreversible deactivation via metal leaching and sintering in the liquid phase as well as their reversible deactivation by poisoning. Leaching and sintering occur preferentially due to the instability 
of undercoordinated metal atoms. Such atoms can also favor byproduct formation due to their high reactivity. These byproducts include coke, in which case these reactive atoms contribute to poisoning the other active sites by initiating the formation of carbon deposits. For these reasons, several authors have reported methods to passivate these undercoordinated atoms using overcoats deposited either by ALD, sugar pyrolysis or CVD, thereby stabilizing the catalyst of interest. Another issue is the leaching and structure modifications of oxide supports due to the poor hydrothermal stability of these solids, which include silica and zeolites. In this case, several authors have turned to fine-tuning the local environment of these catalysts again by physically covering the material of interest. The addition of hydrophobic surface functionalities or overcoats has been shown to reduce support hydrolysis by water molecules. Similarly, depositing a polymeric layer over metal hydrogenation sites was shown to act as an organic pseudo-solvent, which reduced the presence of polar biogenic catalyst poisons and, thus, catalyst deactivation. Finally, increased catalyst lifetime was also improved by process engineering. In fact, tuning the reaction conditions including by lowering $\mathrm{pH}$, or co-feeding organic solvents and hydrogen proved to be efficient for limiting catalyst deactivation.

Further research opportunities exist to combine the principle strategies mentioned above to further improve catalyst stabilization. Tailored overcoats could be used both to stabilize undercoordinated atoms and at the same time to provide favorable microenvironments that could reduce hydrolysis and/or concentrations of catalyst poisons. Such an approach was used in part by adding $\mathrm{MgO}_{\mathrm{x}}$ to reduce the acidity of an alumina overcoat, which was thought to catalyze coke formation, while the overcoat was used to stabilize undercoordinated atoms. However, this approach could be further strengthened by adding functionality to the overcoat and further tailoring the molecular design of the catalyst's local environment. Furthermore, controlling pore size openings within these overcoats could introduce shape selectivity and be used to sieve out undesired reactants as was recently demonstrated for an alumina overcoat on a titania catalyst used for photocatalysis. ${ }^{[84]}$ Finally, it will become increasingly important to use real biomass-derived streams for testing catalytic stability. The negative effects of using liquid or aqueous conditions can be compounded by the presence of numerous, perhaps yet unidentified, inorganic or biogenic impurities. This was notably demonstrated by the accelerated structure collapse of zeolite structures in the presence of inorganic salts.
In summary, current synthetic techniques can lead to unprecedented control of the nanostructures surrounding a catalyst's active site, but harsh conditions present for biomass conversion are equally unprecedented in industrial catalytic processing. As society comes under increasing pressure to develop routes to sustainable carbon-based molecules, these synthetic methods will likely prove essential in addressing the challenges posed by catalytically upgrading renewable resources such as biomass.

\section{Acknowledgements}

The authors acknowledge financial support from the Swiss National Science Foundation through grant number 407040_153866 as part of the National Research Program 70 and grant number PYAPP2_154281 and Benjamin Le Monnier for help with the design of figures.

Received: June 17, 2015

[1] K. Sugiura, M. Ishihara, T. Shimauchi, S. Harayama, Environ. Sci. Technol. 1997, 31, 45.

[2] S. Matar, M. J. Mirbach, H. A. Tayim, 'Catalysis in Petrochemical Processes', Springer Science \& Business Media, 1989

[3] O. S. Abdul-Hamid, Monthly Oil Market Report - May 2015, OPEC, 2015.

[4] The European Parliament and the Council of the European Union, OJ 2009, L140, 16.

[5] R. Rinaldi, F. Schüth, Energy Environ. Sci. 2009, 2,610 .

[6] A. A. Peterson, F. Vogel, R. P. Lachance, M. Fröling, J. Michael J. Antal, J. W. Tester, Energy Environ. Sci. 2008, 1, 32 .

[7] J. S. Luterbacher, D. M. Alonso, J. A. Dumesic, Green Chem. 2014, 16, 4816.

[8] A. Rahimi, A. Ulbrich, J. J. Coon, S. S. Stahl, Nature 2014, 515, 249.

[9] A. Eyal, R. Jansen, R. Mali, A. Vitner, 'Sugar Mixtures and Methods for Production and Use Thereof', 2012, WO 2011161685 A3.

[10] D. V. Kazachkin, M. Colakyan, F. J. Moesler, 'Supercritical Hydrolysis of Biomass', 2015, US 8999065 B2.

[11] D. L. Sills, J. M. Gossett, Bioresour. Technol. 2011, 102, 1389.

[12] D. M. Alonso, S. G. Wettstein, M. A. Mellmer, E. I. Gurbuz, J. A. Dumesic, Energy Environ. Sci. 2012, 6, 76.

[13] J. S. Luterbacher, J. M. Rand, D. M. Alonso, J. Han, J. T. Youngquist, C. T. Maravelias, B. F. Pfleger, J. A. Dumesic, Science 2014, 343, 277.

[14] J. S. Luterbacher, D. M. Alonso, J. M. Rand, Y. M. Questell-Santiago, J. H. Yeap, B. F. Pfleger, J. A. Dumesic, ChemSusChem 2015, 8, 1317.

[15] H. Tadesse, R. Luque, Energy Environ. Sci. 2011, 4, 3913.

[16] J. B. Binder, R. T. Raines, J. Am. Chem. Soc. 2009, 131, 1979 .

[17] J. S. Luterbacher, J. W. Tester, L. P. Walker, Biotechnol. Bioeng. 2010, 107, 451.

[18] D. B. Hodge, M. N. Karim, D. J. Schell, J. D. McMillan, Bioresour. Technol. 2008, 99, 8940.

[19] J. S. Luterbacher, Q. Chew, Y. Li, J. W. Tester, L. P. Walker, Energy Environ. Sci. 2012, 5, 6990.

[20] T. J. Schwartz, B. J. O'Neill, B. H. Shanks, J. A. Dumesic, ACS Catal. 2014, 4, 2060.

[21] G. W. Huber, J. N. Chheda, C. J. Barrett, J. A. Dumesic, Science 2005, 308, 1446.

[22] G. W. Huber, R. D. Cortright, J. A. Dumesic, Angew. Chem. Int. Ed. 2004, 43, 1549.
[23] J. N. Chheda, Y. Román-Leshkov, J. A. Dumesic, Green Chem. 2007, 9, 342.

[24] D. W. Rackemann, W. O. Doherty, Biofuels Bioprod. Biorefining 2011, 5, 198.

[25] J. N. Chheda, G. W. Huber, J. A. Dumesic, Angew. Chem. Int. Ed. 2007, 46, 7164.

[26] A. V. Bandura, S. N. Lvov, J. Phys. Chem. Ref. Data 2006, 35, 15.

[27] H. Xiong, H. N. Pham, A. K. Datye, Green Chem. 2014, 16, 4627.

[28] K. P. De Jong, 'Synthesis Of Solid Catalysts', Wiley-VCH Verlag GmbH \& Co. KGaA, 2009.

[29] F. Héroguel, G. Siddiqi, M. D. Detwiler, D. Y. Zemlyanov, O. V. Safonova, C. Copéret, $J$. Catal. 2015, 321, 81 .

[30] T. W. Hansen, A. T. DeLaRiva, S. R. Challa, A. K. Datye, Acc. Chem. Res. 2013, 46, 1720.

[31] B. J. O'Neill, C. Sener, D. H. K. Jackson, T. F. Kuech, J. A. Dumesic, ChemSusChem 2014, 7, 3247.

[32] B. J. O'Neill, J. T. Miller, P. J. Dietrich, F. G. Sollberger, F. H. Ribeiro, J. A. Dumesic, Chem CatChem 2014, 6, 2493.

[33] B. J. O’Neill, D. H. K. Jackson, A. J. Crisci, C. A. Farberow, F. Shi, A. C. Alba-Rubio, J. Lu, P. J. Dietrich, X. Gu, C. L. Marshall, et al., Angew. Chem. 2013, 125, 14053.

[34] H. Zhang, Y. Lei, A. J. Kropf, G. Zhang, J. W. Elam, J. T. Miller, F. Sollberger, F. Ribeiro, M. C. Akatay, E. A. Stach, J. A. Dumesic, C. L. Marshall, J. Catal. 2014, 317, 284.

[35] H. Zhang, Y. Lei, A. Jeremy Kropf, G. Zhang, J. W. Elam, J. T. Miller, F. Sollberger, F. Ribeiro, M. Cem Akatay, E. A. Stach, J. A. Dumesic, C. L. Marshall, J. Catal. 2015, 323, 165.

[36] J. Lee, D. H. K. Jackson, T. Li, R. E. Winans, J. A. Dumesic, T. F. Kuech, G. W. Huber, Energy Environ. Sci. 2014, 7, 1657.

[37] T. van Haasterecht, C. C. I. Ludding, K. P. de Jong, J. H. Bitter, J. Catal. 2014, 319, 27.

[38] P. Sun, G. Gao, Z. Zhao, C. Xia, F. Li, ACS Catal. 2014, 4, 4136.

[39] J. Lu, B. Fu, M. C. Kung, G. Xiao, J. W. Elam, H. H. Kung, P. C. Stair, Science 2012, 335, 1205.

[40] T. J. Schwartz, R. L. Johnson, J. Cardenas, A. Okerlund, N. A. Da Silva, K. Schmidt-Rohr, J. A. Dumesic, Angew. Chem. Int. Ed. 2014, 53, 12718.

[41] H. N. Pham, A. E. Anderson, R. L. Johnson, K. Schmidt-Rohr, A. K. Datye, Angew. Chem. Int. Ed. 2012, 51, 13163.

[42] H. Xiong, T. J. Schwartz, N. I. Andersen, J. A. Dumesic, A. K. Datye, Angew. Chem. Int. Ed. 2015, early view, DOI 10.1002/anie.201502206.

[43] P. A. Zapata, J. Faria, M. P. Ruiz, R. E. Jentoft, D. E. Resasco, J. Am. Chem. Soc. 2012, 134, 8570.

[44] H. N. Pham, Y. J. Pagan-Torres, J. C. SerranoRuiz, D. Wang, J. A. Dumesic, A. K. Datye, Appl. Catal. Gen. 2011, 397, 153.

[45] Y. J. Pagán-Torres, J. M. R. Gallo, D. Wang, H. N. Pham, J. A. Libera, C. L. Marshall, J. W. Elam, A. K. Datye, J. A. Dumesic, ACS Catal. 2011, $1,1234$.

[46] A. G. Gayubo, B. Valle, A. T. Aguayo, M. Olazar, J. Bilbao, Energy Fuels 2009, 23, 4129.

[47] S. R. Challa, A. T. Delariva, T. W. Hansen, S. Helveg, J. Sehested, P. L. Hansen, F. Garzon, A. K. Datye, J. Am. Chem. Soc. 2011, 133, 20672.

[48] J. A. Moulijn, A. E. van Diepen, F. Kapteijn, Appl. Catal. Gen. 2001, 212, 3.

[49] S. L. Wegener, T. J. Marks, P. C. Stair, Acc. Chem. Res. 2012, 45, 206.

[50] B. J. O'Neill, D. H. K. Jackson, J. Lee, C. Canlas, P. C. Stair, C. L. Marshall, J. W. Elam, T. F. Kuech, J. A. Dumesic, G. W. Huber, ACS Catal. 2015, 5, 1804.

[51] D. M. King, J. A. Spencer II, X. Liang, L. F. Hakim, A. W. Weimer, Surf. Coat. Technol. 2007, 201, 9163. 
[52] J. A. McCormick, B. L. Cloutier, A. W. Weimer, S. M. George, J. Vac. Sci. Technol. A 2007, 25, 67.

[53] D. Longrie, D. Deduytsche, C. Detavernier, $J$. Vac. Sci. Technol. A 2014, 32, 010802.

[54] J. Lu, J. W. Elam, P. C. Stair, Acc. Chem. Res. 2013, 46, 1806.

[55] L. De Rogatis, M. Cargnello, V. Gombac, B. Lorenzut, T. Montini, P. Fornasiero, ChemSusChem 2010, 3, 24.

[56] A. G. Sergeev, J. D. Webb, J. F. Hartwig, J. Am. Chem. Soc. 2012, 134, 20226.

[57] J. He, C. Zhao, J. A. Lercher, J. Am. Chem. Soc. 2012, 134, 20768.

[58] Q. Song, F. Wang, J. Cai, Y. Wang, J. Zhang, W. Yu, J. Xu, Energy Environ. Sci. 2013, 6, 994.

[59] R. Dehghan-Niri, J. C. Walmsley, A. Holmen, P. A. Midgley, E. Rytter, A. H. Dam, A. B. Hungria, J. C. Hernandez-Garrido, D. Chen, Catal. Sci. Technol. 2012, 2, 2476.

[60] M. Morales, P. Y. Dapsens, I. Giovinazzo, J. Witte, C. Mondelli, S. Papadokonstantakis, K. Hungerbühler, J. Pérez-Ramírez, Energy Environ. Sci. 2015, 8, 558.

[61] O. A. Abdelrahman, H. Y. Luo, A. Heyden, Y. Román-Leshkov, J. Q. Bond, J. Catal. 2015, 329, 10.
[62] D. M. Alonso, S. G. Wettstein, J. A. Dumesic, Chem. Soc. Rev. 2012, 41, 8075.

[63] W. Li, L. Ye, P. Long, J. Chen, H. Ariga, K. Asakura, Y. Yuan, RSC Adv. 2014, 4, 29072.

[64] G. Prieto, J. Zečević, H. Friedrich, K. P. de Jong, P. E. de Jongh, Nat. Mater. 2013, 12, 34.

[65] Z. Zhang, J. E. Jackson, D. J. Miller, Bioresour. Technol. 2008, 99, 5873.

[66] H. Luo, T. Prasomsri, Y. Román-Leshkov, Top. Catal. 2015, 394.

[67] J. Mazumder, H. I. de Lasa, Catal. Today 2014, $237,100$.

[68] H. Xiong, H. N. Pham, A. K. Datye, J. Catal. 2013, 302, 93.

[69] H. Xiong, M. Nolan, B. H. Shanks, A. K. Datye, Appl. Catal. Gen. 2014, 471, 165.

[70] P. A. Zapata, Y. Huang, M. A. Gonzalez-Borja, D. E. Resasco, J. Catal. 2013, 308, 82.

[71] A. Corma, Chem. Rev. Wash. DC U. S. 1995, 95 , 559.

[72] P. A. Jacobs, M. Dusselier, B. F. Sels, Angew. Chem. Int. Ed. 2014, 53, 8621.

[73] M. Milina, S. Mitchell, J. Pérez-Ramírez, Catal. Today 2014, 235, 176.

[74] R. M. Ravenelle, F. Schüssler, A. D'Amico, N Danilina, J. A. van Bokhoven, J. A. Lercher, C. W. Jones, C. Sievers, J. Phys. Chem. C 2010 114,19582 .
[75] D. W. Gardner, J. Huo, T. C. Hoff, R. L. Johnson, B. H. Shanks, J.-P. Tessonnier, ACS Catal. 2015, DOI 10.1021/acscatal.5b00888.

[76] P. M. Dove, N. Han, J. J. D. Yoreo, Proc. Natl. Acad. Sci. 2005, 102, 15357.

[77] T. Ennaert, J. Geboers, E. Gobechiya, C. M. Courtin, M. Kurttepeli, K. Houthoofd, C. E. A. Kirschhock, P. C. M. M. Magusin, S. Bals, P. A. Jacobs, B. F. Sels, ACS Catal. 2015, 5, 754.

[78] B. Beverskog, I. Puigdomenech, Corros. Sci. 1997, 39, 969.

[79] D. A. Palmer, P. Bénézeth, C. Xiao, D. J. Wesolowski, L. M. Anovitz, J. Solut. Chem. 2011, 40, 680

[80] J. H. Vleeming, B. F. M. Kuster, G. B. Marin, F. Oudet, P. Courtine, J. Catal. 1997, 166, 148.

[81] A. G. Gayubo, A. T. Aguayo, M. Olazar, R. Vivanco, J. Bilbao, Chem. Eng. Sci. 2003, 58, 5239.

[82] A. de Lucas, P. Canizares, A. Durán, A. Carrero, Appl. Catal. Gen. 1997, 154, 221.

[83] C. Aellig, D. Scholz, P. Y. Dapsens, C. Mondelli, J. Pérez-Ramírez, Catal. Sci. Technol. 2014, 5, 142.

[84] C. P. Canlas, J. Lu, N. A. Ray, N. A. GrossoGiordano, S. Lee, J. W. Elam, R. E. Winans, R. P. Van Duyne, P. C. Stair, J. M. Notestein, Nat. Chem. 2012, 4, 1030 . 